\title{
Spiritual Health and Religious Practices as Correlates to the Quality of Life amongst Faculty and Staff
}

\author{
Micki Angela Villanueva ${ }^{1}$, Chayiel Nuqui ${ }^{2}$, Lea Divina ${ }^{3}$, \\ Rona Beth Saban ${ }^{4}$ and Beryl Ben Mergal $^{5}$ \\ ${ }^{1,2}$ Nursing Student, Adventist University of the Philippines \\ ${ }^{3,4}$ Faculty of Nursing, Adventist University of the Philippines \\ ${ }^{5}$ Research Consultant, Adventist University of the Philippines \\ rbssaban@aup.edu.ph
}

\begin{abstract}
Quality of Life (QOL) is the individual's highly subjective discernment of his position in life in relation to his goals, expectations, and standards. Literatures have consistently reported evidences of association between spirituality and quality of life. But despite the increasing number of studies, only few explore the role of spiritual health and religious practices in the quality of life of faculty and staff of educational institutions. Thus, this descriptivecorrelational study determined the relationship between the spiritual health and religious practices of the respondents and their quality of life. Quality of Life (QOL) is the individual's highly subjective discernment of his position in life in relation to his goals, expectations, and standards. Literatures have consistently reported evidences of association between spirituality and quality of life. But despite the increasing number of studies, only few explore the role of spiritual health and religious practices in the quality of life of faculty and staff of educational institutions. Thus, this descriptive-correlational study determined the relationship between the spiritual health and religious practices of the respondents and their quality of life. The study revealed high levels of spiritual health, religious practices and quality of life of the respondents. Both spiritual health and religious practices were significantly related to the quality of life. Furthermore, married respondents and the teaching faculty had higher level of quality of life compared to those who are unmarried and non-teaching. Lastly, spiritual health is the highest predictor of the quality of life. This study endeavors to help create an environment that would enhance the spiritual health and therefore, the quality of life of the faculty and staff.
\end{abstract}

Keywords: Nursing, Spirituality, Life Satisfaction, Religiosity, Well-Being

\section{INTRODUCTION}

Quality of life is a globally recognized aspiration. People are expected to take steps that will elevate the quality of their lives. Quality of life transcends the concept of multiple domains of health since it can be affected by beliefs, relationships and environment. It is the individual's highly subjective discernment of his position in life in relation to his goals, expectations, 
standards, and concerns. It is a perception of well-being and life satisfaction. It is a widely used concept that pertains to a life considered to be good, well-lived, and of high value (Bruni \& Porta, 2016).

In difficult times, people often look for a sense of meaning and connectedness. Spirituality is that part of one's self that helps a person find meaning and purpose in life, and foster an enduring sense of hope and optimism.

A famous psychologist once said that a critical question for a man is whether or not he is related to something infinite. Only if an individual knows which truly matters and which are not of real importance will he be able to live a satisfying and meaningful life (Jung, 1963). Those words illustrate the main purpose of this particular study: the importance of religious practices and spirituality to the quality of one's life.

Studies found that spiritual health positively and significantly influences quality of life and people with strong religious attitudes tend to have a better quality of life compared to those with weak religious attitudes (Farzaneh Dehghani, Mohammad Seifi, Faezeh Nateghi, \& Alireza Faghihi, 2018; Jafari Poor, Borji, Borji, \& Moslemi, 2016). Evidences show the positive consequences of religious practices. The undeniable influence of religious practices and spirituality in the quality of life has already attracted researchers across a wide array of disciplines. This relationship is set and it appears that it will enjoy some longevity (Peterson \& Webb, 2006).

Literatures have consistently reported evidences of association between spirituality and quality of life. But despite the increasing number of studies on spirituality and quality of life, few studies explore the role of spiritual health and religious practices in the quality of life of faculty and staff of educational institutions. Thus, this descriptive-correlational study is done to determine the relationship between the spiritual health and religious practices of the respondents and their quality of life.

Objectives of the Study

The study aimed to determine the relationship of spiritual health and religious practices of the university faculty and staff, and their quality of life. Specifically, it sought to determine:

1. the level of spiritual health of the faculty and staff;

2. the extent of religious practices of the faculty and staff;

3. the quality of life of the faculty and staff;

4. the relationship between the spiritual health and religious practices of the faculty and staff, and their quality of life; 
5. the difference in the quality of life of the faculty and staff when gender, educational attainment, marital status, and work position are considered;

6. the variables that significantly predict quality of life.

\section{LITERATURE REVIEW}

Spiritual Health

It has been several decades since the term "spiritual health" was coined. Review of literatures showed efforts to explain this important concept in different perspectives, resulting to various meanings (Akbari \& Hossaini, 2018; Ghaderi, Tabatabaei, Nedjat, Javadi, \& Larijani, 2018). However, in spite of the different studies about spiritual health, a satisfying, concrete and comprehensive definition which has the same intensity as the other dimensions of health is relatively few (Akbari \& Hossaini, 2018; Bensley, 1991; Vader, 2006). In an attempt to provide definition and indicators of spiritual health in the experts' perspectives, Ghaderi et al. (2018) came up with a qualitative study, proposing that spiritual health dominates the other aspects of health. The finding of the study further revealed that there are four types of connection in spiritual health: human connection with God, himself, others, and nature. Moreover, most experts who participated in the study, acknowledged that the most significant dimension of the spiritual health is the human connection with God.

Dr. Fahri Karakas (2010) reviewed 140 papers on workplace spirituality to determine how spirituality influence organization performance. Three different perspectives were introduced based on the literature review: first, spirituality enhances well-being and quality of life of employees; secondly, spirituality provides a sense of purpose and meaning at work; and lastly, spirituality provides employees a sense of interconnectedness.

Spiritual health is a strong condition of life, which knows how much society lives in the coherence contained in relationships. Although spirituality and religion are often overlapping related ideas, it is unthinkable to isolate spiritual ideas from the extraordinary characteristics of life. Spirituality aims to calm and purify the spirit. Therefore, if individuals can calm and purify their minds in a state of calm and harmony, through spiritual guidance, they will be able to solve the problems of life and find a way of balance and direction. Spiritual health is one of the factors that affects the quality of life of many people. People who have spiritual health may have a better quality of life (Purdy \& Dupey, 2005) and, as spirituality can help individuals find meaning in life and improve their psychological health, they will develop better habits leading to a better lifestyle. Based on statistics, it is established that spiritual health is a 
complete mediator of life attitudes and well-being. In other words, the attitude of life leads to prosperity through spiritual health. Therefore, in practice, teachers must first adopt a positive attitude, followed by an assessment of improvement of spiritual health, so as to be able to achieve well-being (Chou, Tsai, Hsu, \& Wu, 2016).

\section{Religious Practices}

In a survey about religious practices and experiences of Americans done by Pew Research Center (2015), the researchers recognized the following as the different forms of religious observance: worship service attendance, congregational membership, scripture study or prayer groups, private devotions, sharing one's faith, observance of religion's restrictions, and spiritual experiences such as feelings of spiritual peace and sense of well-being. The findings revealed that worship attendance and personal devotions/prayers have both been very stable since 2007 among those who are affiliated with a religion. It also showed an increasing percentage of individuals who share their faith regularly, and who felt a deep sense of spiritual peace and well-being.

Evidences show positive impacts of religious practices. Regular church attendance is a significant predictor of marital satisfaction, stability, and happiness. Religious beliefs and regular religious practices largely contributes to moral development, provides immunity against social problems, and offers beneficial effects on mental health: reduced depression, increased self-esteem (Fagan, 1996)

Religious practices play a significant role in making individuals aware of religion's significance. Moreover, religious convictions, values, and procedures have an impact on financial life, family, community, and social interactions. Religion plays an important role in social relations in the public eyes (Bruni \& Porta, 2016). Religious practices are based on the heart of religious experience, which is the basis of the attitude or sustainability of an individual (Seeman, Dubin, \& Seeman, 2003).

Many people view religion and spirituality as important sources for dealing with stressful lives. To do without spiritual well-being, other dimensions that contribute to an individual's health are unable to function properly or reach their absolute threshold. Religious belief comforts human beings as it provides peace of mind, bridges emotional, moral and spiritual gaps and strengthen the individual and society's major dimensions (Jafari Poor et al., 2016). 
Quality of Life

World Health Organization (WHO) has defined quality of life as an individual's perception of their position in life of an individual's in the context of the culture and value systems in which they live and their goals, expectations, norms and concerns. It is believed to be a wide notion that includes intricately physical health, psychological state, level of independence, social relationships, personal beliefs, and private relationships of an individual with vital environmental features ("WHO | WHOQOL: Measuring quality of life," 2014).

Quality of life is a widely used multidimensional concept that deals with the subjective evaluations of both negative and positive aspects of life (Bruni \& Porta, 2016; Centers for Disease Control and Prevention, 2000). It is related to one's mental perception of well-being and satisfaction with life (Fernandes \& Rocha, 2009). It pertains to a good, well-lived, and valuable life, or those conditions that promote such life of high quality (Bruni \& Porta, 2016). Studies have progressed from the original method of focusing on the quality of life of entire populations to recognize the importance and quality of life as an individual attribute. As a result of this shift in the study of populations towards an individual point of view, researchers are focusing more on a subjective experience of quality from an individual's point of view (Williams et al., 2017).

\section{METHODS}

\section{Research Design}

The study used a descriptive-correlational design. This descriptive-correlational method is an interrogative that involves sufficient and precise analysis of findings, and describes the present condition of the faculty and staff. It involves gathering data that describes events which then later organizes and depicts the data collection (O’Dwyer \& Bernauer, 2016).

Population and Sampling Technique

Through purposive sampling, 177 faculty and staff from different departments of the university were selected. The researchers distributed and received questionnaires from the faculty and staff who are currently working in the university for at least 6 months. The respondents consist of $93(52.5 \%)$ faculty and $84(47.5 \%)$ staff. There are $76(42.9 \%)$ males, and $101(57.1 \%)$ females. Majority (101) of the respondents are married which accounts for $73.4 \%$ of the population; while $43(24.3 \%)$ are single, and $4(2.3 \%)$ are widowed. Among the 177 
respondents, 77 (43.5\%) are College graduates, 71 (40.1\%) are Master's degree holder, and 29 (16.4) are Doctoral degree holder.

Instrumentation

The instrument is divided into four parts. A constructed questionnaire was used to determine the demographic profile of the respondents and to measure the extent of their religious practices. Two parts of the questionnaire were adapted from existing instruments found in the literatures. Permission to use the adapted questionnaires were obtained from the corresponding authors. Modification in some parts of the questionnaire were done to cater the uniqueness of the respondents.

The first part of the instrument is the demographic profile of the faculty and staff, which includes the age, gender, marital status, educational attainment, and their work position (teaching or non-teaching) in the school.

The second part of the instrument is adapted from the World Health Organization's Quality of Life Instrument. WHOQOL-BREF is an abbreviated generic Quality of Life Scale developed by the WHOQOL group, and is a shorter version of the original WHOQOL 100-item questionnaire ("WHO | The World Health Organization Quality of Life (WHOQOL)," 2019). The instrument is composed of 26 items which measures physical health, psychological health, social relationships, and environment. It has undergone rigorous reliability and validity testing which yielded positive results. The WHOQOL-BREF performs well in preliminary tests of validity, it shows good to excellent psychometric properties of reliability, and is considered a cross-culturally valid assessment of Quality of Life (Skevington, Lotfy, \& O'Connell, 2004). The third part of the instrument is the measure of the frequency of the religious practices of an individual.

The last part of the instrument is adapted from Spiritual Health and Life Orientation Measure (SHALOM) Questionnaire. The instrument was developed based on the four domains model of spiritual health and well-being. SHALOM is composed of 20 items with five items evaluating the relationship of each person with himself (personal), others (communal), nature (environmental, and with God (transcendental) (Fisher, 2010; Mathad, Rajesh, \& Pradhan, 2019). The instrument has been widely utilized by diverse populations and has undergone exhaustive statistical testing to ensure validity and reliability. SHALOM offers a unique assessment of spiritual well-being by providing a measure of spiritual accord or discord in each of the domains and by associating each person's ideals with their lived experiences (Fisher, 2010). 


\section{Data Gathering Procedures}

An approval was secured prior to the conduction of the study. The researchers distributed the questionnaires by approaching the faculty and staff in all the departments of the university. A consent form was issued for respondents' privacy. The purpose of the study was given for the respondent's awareness and cooperation. Clarifications about the instructions and questions were addressed before and while the survey was being answered to avoid confusion and unnecessary error. The questionnaires were retrieved and were confidentially secured.

\section{Ethical Considerations}

This study was conducted in conformance with the principles of human research ethics. The study has been subjected to ethics review by the Ethics Review Board (ERB) of the Institution. The ethical principles were carefully reviewed to uphold the dignity of the respondents. An informed consent was utilized prior to the actual data gathering. The approval protocol for this study was 2019-AUP-054.

The identity of the participants was hidden to the researchers own keeping. The participants were fully informed and the researchers checked to see if the faculty and staff fully grasped the aim of the study. The answers of each respondent were kept confidential, along with their identity and name. The information collected from this research study were kept confidential. Information about the participants collected during the research were coded with an assigned number and stored in such a way that only the researcher and the adviser will be able to access it. It was not shared with or given to anyone unless required for publication.

In the event that publication is required, all personal information shall not be divulged but coded identity may be declared. The potential risks of this study are the questions in the survey that may tackle personal issues of the participant. In any case that the participant feels uncomfortable, the researchers may reassure that all of the collected data will be kept confidential. The respondents may choose to withdraw from the research, and choose not to answer any question or participate in the debate, interview, or survey if he or she feels the question(s) are too personal or if it makes him or her awkward or uncomfortable towards themselves. The benefit of participating is to help the researchers find answer to the research question. Future generations are more likely to benefit by utilizing the result of the 
study as the basis for developing programs that will attract and encourage faculty to engage in scholarly works.

\section{Analysis of Data}

The information collected for the outcomes were statistically tested, evaluated, and summarized. Descriptive statistics were used to determine the faculty and staff's demographic profile, the level of spiritual health, the extent of their religious practices, and the respondent's quality of life. Pearson's correlation coefficient was used to determine the significance of the relationship between the independent and dependent variables, as well as the strength of the association between the two (Wang, 2013). Analysis of Variance (ANOVA) and t-test were used to determine the difference in the quality of life of respondents considering their marital status, gender, educational attainment, and their work position as a faculty or staff. Linear regression was used to determine the variable(s) that mostly predicted the quality of life of the respondents.

\section{RESULTS AND DISCUSSION}

Spiritual Health

Spiritual health has been widely accepted as a component of health. It can be considered as the dimension that directs the other components of health to a higher level. Spiritual health also promotes a good life and a more positive outlook (Anye, Gallien, Bian, \& Moulton, 2013). It is established that spiritual health is a complete mediator of life attitudes and well-being (Chou et al., 2016).

\section{Table 5. Spiritual Health of the Faculty and Staff}

\begin{tabular}{lccc}
\hline \multicolumn{1}{c}{ Question } & Mean & SD & VI \\
\hline Love of other people & 4.19 & .681 & High \\
Personal relationship with the Divine & 4.30 & .720 & High \\
Forgiveness toward others & 4.23 & .655 & High \\
Connection with nature & 4.20 & .771 & High \\
A sense of identity & 4.24 & .644 & High \\
Worship of the Creator & 4.50 & .633 & Very High \\
Awe at a breathtaking view & 4.21 & .788 & High \\
Trust between individuals & 3.86 & .721 & High \\
Self-awareness & 4.19 & .616 & High \\
Oneness with nature & 4.12 & .712 & High \\
Oneness with God & 4.33 & .712 & High \\
Harmony with the environment & 4.21 & .698 & High \\
Peace with God & 4.49 & .613 & High \\
& 454 & &
\end{tabular}


Joy in life

Prayer life

Inner peace

Respect for others

Meaning in life

Kindness towards other people

A sense of 'magic' in the environment
4.31

4.28

4.24

4.44

4.31

4.35

4.05
.639

.721

.715

.562

.630

.613

.813
High

High

High

High

High

High

High

Legend: $4.5-5=$ Very high $; 3.5-4.49=$ high $; 2.50-3.49=$ moderate $; 1.50-2.49=$ low; $1.00-1.49=$ very low $;$ VI Verbal Interpretation

Table 5 shows that the university employees have a high level of spiritual health, $M=4.25$ $(\mathrm{SD}=.487)$. The highest among all the indicators of their spiritual health is the respondents' worship of the Creator $(\mathrm{M}=4.50, \mathrm{SD}=.633)$.

In an attempt to provide definition and indicators of spiritual health in the experts' perspectives, a qualitative study was done and proposed that spiritual health dominates the other aspects of health. The finding of the study further revealed that there are four types of connection in spiritual health: human connection with God, himself, others, and nature. Most experts who participated in the study, acknowledged that the most significant dimension of the spiritual health is the human connection with God (Ghaderi et al., 2018). The findings are consistent with the results of this particular study.

If the spiritual dimension of health is disregarded, the force needed to empower the individuals to attain physical, social, and mental health might vanish (Vader, 2006).

People can improve their spiritual well-being and quality of life by participating in spiritual self-care activities (White, 2016). Spiritual personal care activities may include social networking or volunteering, listening to inspirational music, meditation, and developing a sense of inner peace and quiet Spiritual well-being is seen as an important approach in promoting health in general and quality of life and as one of the basic concepts of the chronicle to create meaning and tenacity in life. Cultural and religious beliefs may be useful and necessary in designing care programs for certain individuals who are attached to their spiritual health and other areas of health (Allahbakhshian, Jafarpour, \& Parvizi, 2011).

\section{Religious Practices}

In a survey about religious practices and experiences of Americans done by Pew Research Center (2015), the researchers recognized the following as the different forms of religious observance: worship service attendance, congregational membership, scripture study or prayer groups, private devotions, sharing one's faith, observance of religion's restrictions, and 
spiritual experiences such as feelings of spiritual peace and sense of well-being. The findings revealed that worship attendance and personal devotions/prayers have both been very stable since 2007 among those who are affiliated with a religion. It also showed an increasing percentage of individuals who share their faith regularly, and who felt a deep sense of spiritual peace and well-being.

Table 6. Extent of Religious Practices of Faculty and staff

\begin{tabular}{lccc}
\hline \multicolumn{1}{c}{ Question } & Mean & SD & VI \\
\hline How often do you do personal bible reading? & 2.81 & 1.208 & Moderate \\
How often do you have personal/family worship? & 3.31 & 1.187 & Moderate \\
How often do you attend Sabbath worship? & 4.72 & .610 & Very High \\
How often do you pray personally? & 4.18 & .891 & High \\
How often do you do personal bible reading? & 3.44 & .987 & Moderate \\
\hline \multicolumn{1}{c}{ Total } & $\mathbf{3 . 6 9}$ & $\mathbf{. 6 7 6}$ & High \\
\hline
\end{tabular}

Legend: $4.5-5=$ Very high $; 3.5-4.49=$ high $; 2.50-3.49=$ moderate $; 1.50-2.49=$ low $; 1.00-1.49=$ very low; VI - Verbal Interpretation

Table 6 shows a high extent of religious practices of the faculty and staff $(\mathrm{M}=3.69, \mathrm{SD}=.676)$. In particular, the respondents placed a very high value in attending Sabbath worship $(\mathrm{M}=4.72$, $\mathrm{SD}=.610$ ). On the other hand, personal bible reading appeared to be the practice with the lowest extent $(\mathrm{M}=2.81, \mathrm{SD}=1.208)$.

Evidences show positive impacts of religious practices. Regular church attendance is a significant predictor of marital satisfaction, stability, and happiness. Religious beliefs and regular religious practices largely contributes to moral development, provides immunity against social problems, and offers beneficial effects on mental health: reduced depression, increased self-esteem (Fagan, 1996).

Many people view religion and spirituality as important sources for dealing with stressful lives. To do without spiritual well-being, other dimensions that contribute to an individual's health are unable to function properly or reach their absolute threshold. Religious belief comforts human beings as it provides peace of mind, bridges emotional, moral and spiritual gaps and strengthen the individual and society's major dimensions (Jafari Poor et al., 2016).

\section{Quality of Life}

World Health Organization (WHO) has defined quality of life as an individual's perception of their position in life of an individual's in the context of the culture and value systems in which 
they live and their goals, expectations, norms and concerns. It is believed to be a wide notion that includes intricately physical health, psychological state, level of independence, social relationships, personal beliefs, and private relationships of an individual with vital environmental features (“WHO | WHOQOL: Measuring quality of life," 2014).

\section{Table 7. Quality of Life of the Faculty and Staff}

\begin{tabular}{|c|c|c|c|}
\hline Question & Mean & SD & VI \\
\hline Physical pain prevents me from doing what I need to do & 3.61 & 1.093 & Low \\
\hline I need medical treatment to function in life & 4.08 & 1.102 & Low \\
\hline I enjoy life & 4.20 & .731 & High \\
\hline I feel that my life is meaningful & 4.28 & .674 & High \\
\hline I am able to concentrate well & 3.98 & .723 & High \\
\hline I feel safe in my daily life & 4.14 & .674 & High \\
\hline My physical environment is healthy & 4.12 & .720 & High \\
\hline I have enough energy for the day & 4.12 & .659 & High \\
\hline I accept my body appearance & 4.28 & .831 & High \\
\hline I have enough money to meet my needs & 3.36 & .874 & Moderate \\
\hline $\begin{array}{l}\text { I have available information that I need in my day-to-day } \\
\text { life }\end{array}$ & 3.90 & 622 & High \\
\hline I have time for leisure activities & 3.19 & .938 & Moderate \\
\hline Are you able to get around with others & 3.77 & .865 & High \\
\hline How satisfied are you with your sleep? & 3.72 & .946 & High \\
\hline $\begin{array}{l}\text { How satisfied are you with your ability to perform your } \\
\text { daily living activities? }\end{array}$ & 4.10 & 609 & High \\
\hline How satisfied are you with your capacity for work? & 4.23 & .589 & High \\
\hline How satisfied are you with yourself? & 4.28 & 639 & High \\
\hline How satisfied are you with your personal relationships? & 4.13 & .725 & High \\
\hline How satisfied are you with your sex life? & 3.78 & .993 & High \\
\hline $\begin{array}{l}\text { How satisfied are you with the support you get from your } \\
\text { friends? }\end{array}$ & 4.15 & .663 & High \\
\hline $\begin{array}{l}\text { How satisfied are you with the conditions of your living } \\
\text { place? }\end{array}$ & 3.95 & .806 & High \\
\hline How satisfied are you with your access to health services? & 3.93 & .717 & High \\
\hline How satisfied are you with your mode of transportation? & 4.07 & .691 & High \\
\hline Total & 3.97 & .402 & High \\
\hline
\end{tabular}

Legend: $4.5-5=$ Very high $; 3.5-4.49=$ high $; 2.50-3.49=$ moderate $; 1.50-2.49=$ low; $1.00-1.49=$ very low $; \mathrm{VI}-$ Verbal Interpretation

Table 7 shows a high level of the quality of life of the faculty and staff $(\mathrm{M}=3.97, \mathrm{SD}=.402)$. The positive result of this study is heartwarming, considering that work demands and stresses of academic institution workers may cause various health consequences and may compromise their quality of life (Fernandes \& Rocha, 2009).

Quality of life is a widely used multidimensional concept that deals with the subjective evaluations of both negative and positive aspects of life (Bruni \& Porta, 2016; Centers for Disease Control and Prevention, 2000). It is related to one's mental perception of well-being 
and satisfaction with life (Jafari Poor et al., 2016). It pertains to a good, well-lived, and valuable life, or those conditions that promote such life of high quality (Bruni \& Porta, 2016) Studies have progressed from the original method of focusing on the quality of life of entire populations to recognize the importance and quality of life as an individual attribute. As a result of this shift in the study of populations towards an individual point of view, researchers are focusing more on a subjective experience of quality from an individual's point of view. Quality of Life at Work (QWL) refers to the degree of satisfaction and contentment an employee feels about their work and the work situation in general. Research suggests that there is a high level of stress in academic institutions (Williams et al., 2017). How a worker perceives workplace culture and healthy lifestyle beliefs influences healthy living behaviors in faculty and staff at a university.

Relationship of Spiritual Health and Religious Practices to Quality of Life

Although spirituality and religion often overlap, it is unthinkable to isolate spiritual ideas from the extraordinary characteristics of life. More and more research has shown that religious involvement is linked to better physical health, better mental health and longer survival. Both transversely and prospectively. These relationships remain statistically significant (Jafari Poor et al., 2016).

Table 8. Relationship of Spiritual Health and Religious Practices to Quality of Life

\begin{tabular}{ccc}
\hline Variable & Components & Quality of Life \\
\hline Spiritual & Pearson Correlation & $.564^{* *}$ \\
Health & p-value & $<0.001$ \\
& $\mathrm{~N}$ & 177 \\
& Verbal Interpretation & Significant \\
Religious & Pearson Correlation & $.412^{* *}$ \\
Practice & p-value & $<0.001$ \\
& $\mathrm{~N}$ & 177 \\
& Verbal Interpretation & Significant \\
\hline
\end{tabular}

Table 8 shows the relationship between spiritual health and religious practices to the quality of life. Results says that there is a significant relationship between spiritual health to quality of life $(\mathrm{p}=<0.001)$ and religious practices to quality of life $(\mathrm{p}=<0.001)$. The same is true with the findings of the research conducted by Akbari and Hossaini (2018) which revealed a strong connection between spiritual health and quality of life. The study further emphasized that 
religious and spiritual beliefs and activities can lessen the stresses of life, and will provide meaning and hope, thereby promoting a life of good quality. Based on the literature review of 140 papers on workplace spirituality by Dr. Fahri Karakas, spirituality influence organization performance. The specific results of the review support the findings found on the table above. According to the study, spirituality enhances well-being and quality of life, it makes work life meaningful, and it provides a sense of purpose and interconnectedness (Karakas, 2010). There is also an evidence that religion and spirituality can be a protection against risky health behaviors which in turn contribute to enhancing the quality of life (Anye et al., 2013; Mohebbifar, Pakpour, Nahvijou, \& Sadeghi, 2015)

Table 9. Quality of Life of Faculty and Staff when Educational Attainment is Considered

\begin{tabular}{cccccccc}
\hline Groups & N & Mean & SD & df & F & p-value & VI \\
\hline College & 77 & 3.89 & 0.38 & 2,173 & 2.876 & 0.059 & Not Significant \\
Masters & 71 & 4.01 & 0.40 & & & & \\
Doctorate & 29 & 4.08 & 0.43 & & & & \\
Legend: $S D-$ Standard Deviation VI - Verbal Interpretation & & &
\end{tabular}

Table 9 shows the relationship between educational attainment to quality of life. Results showed that there is no significant relationship between educational attainment and quality of life ( $\mathrm{p}=0.059)$. Educational achievement is often evaluated by the amount of years. Years of education or the greatest degree. However, many commentators have pointed out that such policies do not properly represent all appropriate educational elements, such as variations in the quality of education. Higher education is closely linked to the extent to which both sexes thrive in their life (Jongbloed, 2018).

Table 10. Quality of Life of Faculty and Staff when Gender is Considered

\begin{tabular}{cccccccc}
\hline Gender & N & Mean & SD & T & df & p-value & VI \\
\hline Male & 76 & 3.94 & 0.38 & -0.84 & 175 & 0.404 & Not Significant \\
Female & 101 & 4.00 & 0.42 & & & & \\
\cline { 5 - 6 } Legend: $S D-$ Standard Deviation VI - Verbal Interpretation & & &
\end{tabular}

Table 10 shows the relationship between gender to quality of life. Results showed that there is no significant relationship between gender and quality of life $(\mathrm{p}=0.404)$.

In a literature, women outperform men in many verbal assessments and are more emotionally expressive, docile and timid than men. Men tend to be more active and more aggressive 
physically and verbally than women and tend to outperform them in arithmetic reasoning tests and visual and spatial abilities. Men tend to be more focused on fitness and other internal factors, while women tend to concentrate on effort and external factors (Vecchione, Alessandri, \& Marsicano, 2014). Autonomy also proved to be different between the sexes since men were more associated with greater parental disobedience. In spite of the differences between the sexes, men and women are much more psychologically similar than different.

Table 11. Quality of Life of Faculty and Staff when Marital Status is Considered

\begin{tabular}{cccccccc}
\hline Groups & N & Mean & SD & df & F & p-value & VI \\
\hline Single & 43 & 3.91 & 0.37 & 2,173 & 7.118 & 0.001 & Significant \\
Married & 130 & 4.01 & 0.38 & & & & \\
Widowed & 4 & 3.31 & 0.74 & & & & \\
Legend: $S D-$ Standard Deviation & VI - Verbal Interpretation
\end{tabular}

Table 11 shows the relationship between marital status and quality of life. Results indicate that there is a significant difference in the quality of life of the respondents when marital status is considered $(\mathrm{p}=0.001)$. Highest quality of life is seen in married respondents $(\mathrm{M}=4.01$, $\mathrm{SD}=0.38)$.

One study on the association of marital status with the quality of life showed that single men had a significantly worse quality of life in comparison to married men. This literature also found there to be a significant relationship between the quality of life, and the marital status, which also appeared to differ by age and gender (Han, Park, Kim, Kim, \& Park, 2014). Marital quality is strongly linked to subjective well-being and is generally greater in females than in males (Jackson, Miller, Oka, \& Henry, 2014).

Table 12. Quality of life of Faculty and Staff when Work Position is considered

\begin{tabular}{cccccccc}
\hline Work position & $\mathbf{N}$ & Mean & SD & t & df & p-value & VI \\
\hline Faculty & 93 & 4.05 & 0.41 & 2.67 & 175 & 0.008 & Significant \\
Staff & 84 & 3.89 & 0.38 & 0.04 & & & \\
\\
Legend: $S D-$ Standard Deviation VI - Verbal Interpretation
\end{tabular}

Table 12 shows that there is a significant difference in the quality of life of the respondents when work position is considered $(\mathrm{p}=0.008)$. The results indicate that the faculty has a higher quality of life $(\mathrm{M}=4.05, \mathrm{SD}=0.41)$ compared to the staff.

Quality of Life at Work (QWL) refers to the degree of satisfaction and contentment an employee feels about their work and the work situation in general. Research suggests that there 
is a high level of stress in academic institutions (Williams et al., 2017). Negative associations between the psychosocial aspects of work and the quality of life were reported in a crosssectional study of 1,319 workers aged 18 to 64 (Nappo, 2019). The findings showed a substantial statistical association between the variable employment supply (high demand and low control) and low scores in the following areas of quality of life: functional ability, physical constraints, vitality, social and mental health elements (Alves, Oliveira, \& Paro, 2019).

How a worker perceives workplace culture and healthy lifestyle beliefs influences healthy living behaviors in faculty and staff at a university. Interventions to enhance health results and decrease the cost of health care for professors and employees at a university are crucial (Melnyk, Amaya, Szalacha, \& Hoying, 2016).

The Predictor of Quality of Life

In an attempt to determine the predictors of quality of life, the existing independent and moderating variables were utilized for further analysis. Table 13 shows the most significant predictor of the quality of life.

Table 13. Predictor of the Quality of Life of the respondents

\begin{tabular}{ccccccc}
\hline Predictor & $\begin{array}{c}\text { Sum of } \\
\text { Squares }\end{array}$ & df & Coefficient & $\begin{array}{c}\text { R } \\
\text { Square }\end{array}$ & t & p-value \\
\hline Constant & 9.239 & 1 & & & & \\
Spiritual & 17.962 & 164 & 1.851 & 0.34 & 7.98 & $<0.001$ \\
Health & 27.201 & 165 & 0.498 & & 9.184 & $<0.001$ \\
\hline
\end{tabular}

The study finds that spiritual health is the most significant predictor of quality of life $(\mathrm{p}=<0.001)$. Several studies compiled by Mohebbifar, Pakpour, Nahvijou, \& Sadeghi (2015) and Jafari Poor et al. (2016), are consistent with the result of this present study. Their research on different individuals in different conditions revealed a positive and significant relationship between the spiritual health and quality of life. Another study which evaluated the interaction of spiritual health with other dimensions also shows that spiritual health is one of the most significant predictors of quality of life (Akbari \& Hossaini, 2018).

According to Purdy and Dupey (2005), people with spiritual health may have better quality of life, and since spirituality can assist people to discover significance in life and enhance their psychological health, they will create better practices that lead to a better lifestyle. 
The consistency between the results obtained in this present study and the literatures reviewed suggests that quality of life is truly influenced by spiritual health which is directly related to an individual's faith in God and a purposeful and meaningful life.

\section{Conclusion}

The main objective of the study is to determine the influence of spiritual health and religious practices on the quality of life of university employees. After analysis of data, findings revealed that the respondents are spirituality healthy, their religious practices are to a high extent, and they possess high quality of life. The results also showed that there is a significant relationship between the spiritual health and religious practices of the respondents and their quality of life. Furthermore, there is a significant difference in the quality of life of the faculty and staff when work position and marital status are considered. Those who are teaching and married have higher quality of life compared to those who are nonteaching and unmarried. Lastly, the study identified spiritual health as the highest predictor of the quality of life.

Since the faculty and staff are employees in a sectarian university, it is not surprising that spiritual health and religious practices have a significant influence in their quality of life. Although there are other factors that affects quality of life, it is still safe to conclude, based on the findings of this study, that actions should be undertaken to maintain or enhance the spiritual health and religious practices of the university employees. The findings suggest that the quality of life of the faculty and staff as influenced by the spiritual health, should be considered as one of the central priorities of academic institutions.

At a time in which academic institutions are faced with strong competitions, high demands, great expectations, major change, and boundless complexities than ever before, ensuring and enhancing spiritual health is truly a great need. It is the researchers' humble hope that the institution, together with its leaders and employees will aspire to enhance the quality of their lives through application and incorporation of spiritual values, compassion, inspiration, and reflection in the workplace.

This study endeavors to help create an environment that would promote spiritual health of the faculty and staff, therefore, bringing them a step closer to that pursuit of a life of quality.

\section{REFERENCES}

Akbari, M., \& Hossaini, S. M. (2018). The relationship of spiritual health with quality of life, 
mental health, and burnout: The mediating role of emotional regulation. Iranian Journal of Psychiatry, 13(1), 22-31. Retrieved from http://web.b.ebscohost.com/ehost/pdfviewer/pdfviewer?vid=6\&sid=72b6702e-33e24ca6-ae5e-74ff0f194f1a\%40pdc-v-sessmgr05

Allahbakhshian, M., Jafarpour, M., \& Parvizi, S. (2011). Spiritual well-being of patients with multiple sclerosis. Iranian Journal of Nursing and Midwifery Research, 16(3), 202206. Retrieved from http://www.ncbi.nlm.nih.gov/pubmed/22224107

Alves, P. C., Oliveira, A. de F., \& Paro, H. B. M. da S. (2019). Quality of life and burnout among faculty members: How much does the field of knowledge matter? PloS One, 14(3), e0214217. https://doi.org/10.1371/journal.pone.0214217

Anye, E. T., Gallien, T. L., Bian, H., \& Moulton, M. (2013). The relationship between spiritual well-being and health-related quality of life in college students. Journal of American College Health, 61(7), 414-421. https://doi.org/10.1080/07448481.2013.824454

Bensley, R. J. (1991). Defining spiritual health: A review of the literature. Journal of Health Education, 22(5), 287-290. https://doi.org/10.1080/10556699.1991.10614636

Bruni, L., \& Porta, P. L. (2016). Handbook of research methods and applications in happiness and quality of life. Cheltenham: Edward Elgar Publishing Limited.

Centers for Disease Control and Prevention. (2000). HRQOL Concepts | CDC. In Centers for Disease Control and Prevention. Retrieved from https://www.cdc.gov/hrqol/concept.htm

Chou, M.-J., Tsai, S.-S., Hsu, H.-M., \& Wu, H.-T. (2016). Research on correlation between the life attitude and wellbeing - with spiritual health as the mediator. European Journal of Research in Social Sciences, 4(3), 76-88. Retrieved from https://www.idpublications.org/wp-content/uploads/2016/03/RESEARCH-ONCORRELATION-BETWEEN-THE-LIFE-ATTITUDE-AND-WELL-BEING-FullPaper.pdf

Fagan, P. (1996). Why Religion Matters: The Impact of Religious Practice on Social Stability | The Heritage Foundation. Retrieved from https://www.heritage.org/civilsociety/report/why-religion-matters-the-impact-religious-practice-social-stability

Farzaneh Dehghani, Mohammad Seifi, Faezeh Nateghi, \& Alireza Faghihi. (2018). The effectiveness of happiness training on improving the quality of life of women in Pars Special Economic Zone staffs based on their religious attitudes. Iranian Journal of Educational Sociology, 1(9), 48-59. Retrieved from http://iase-idje.ir/article-1-209en.pdf

Fernandes, M. H., \& Rocha, V. M. da. (2009). Impact of the psychosocial aspects of work on the quality of life of teachers. Revista Brasileira de Psiquiatria, 31(1), 15-20. https://doi.org/10.1590/S1516-44462009000100005

Fisher, J. (2010). Development and Application of a Spiritual Well-Being Questionnaire Called 
SHALOM. Religions, 1(1), 105-121. https://doi.org/10.3390/rel1010105

Ghaderi, A., Tabatabaei, S. M., Nedjat, S., Javadi, M., \& Larijani, B. (2018). Explanatory definition of the concept of spiritual health: a qualitative study in Iran. Journal of Medical Ethics and History of Medicine, 11, 3. Retrieved from http://www.ncbi.nlm.nih.gov/pubmed/30258553

Han, K.-T., Park, E.-C., Kim, J.-H., Kim, S. J., \& Park, S. (2014). Is marital status associated with quality of life? Health and Quality of Life Outcomes, 12(1), 109. https://doi.org/10.1186/s12955-014-0109-0

Jackson, J. B., Miller, R. B., Oka, M., \& Henry, R. G. (2014). Gender differences in marital satisfaction: A meta-analysis. Journal of Marriage and Family, 76(1), 105-129. https://doi.org/10.1111/jomf.12077

Jafari Poor, H., Borji, M., Borji, M., \& Moslemi, A. (2016). The relationship between spiritual well-being and quality of life and optimism on the staff of Arak University of Medical Sciences 2012. Health, Spirituality and Medical Ethics, 3(2), 8-15. Retrieved from http://jhsme.muq.ac.ir/browse.php?a_id=86\&sid=1\&slc_lang=en

Jongbloed, J. (2018). Higher education for happiness? Investigating the impact of education on the hedonic and eudaimonic well-being of Europeans. European Educational Research Journal, 17(5), 733-754. https://doi.org/10.1177/1474904118770818

Jung, C. G. (Carl G. (1963). Memories, dreams, reflections. Retrieved from https://books.google.com.ph/books?id=2znTYOMXMHwC\&dq=memories dreams reflections\&source=gbs_book_other_versions

Karakas, F. (2010). Spirituality and performance in organizations: A literature review. Journal of Business Ethics, 94(1), 89-106. https://doi.org/10.1007/s10551-009-0251-5

Mathad, M. D., Rajesh, S. K., \& Pradhan, B. (2019). Spiritual Well-Being and Its Relationship with Mindfulness, Self-Compassion and Satisfaction with Life in Baccalaureate Nursing Students: A Correlation Study. Journal of Religion and Health, 58(2), 554565. https://doi.org/10.1007/s10943-017-0532-8

Melnyk, B. M., Amaya, M., Szalacha, L. A., \& Hoying, J. (2016). Relationships among perceived wellness culture, healthy lifestyle beliefs, and healthy behaviors in university faculty and staff. Western Journal of Nursing Research, 38(3), 308-324. https://doi.org/10.1177/0193945915615238

Mohebbifar, R., Pakpour, A. H., Nahvijou, A., \& Sadeghi, A. (2015). Relationship between spiritual health and quality of life in patients with cancer. Asian Pacific Journal of Cancer Prevention: APJCP, 16(16), 7321-7326. https://doi.org/10.7314/apjcp.2015.16.16.7321

Nappo, N. (2019). Is there an association between working conditions and health? An analysis of the Sixth European Working Conditions Survey data. PLOS ONE, 14(2), e0211294. https://doi.org/10.1371/journal.pone.0211294 
O’Dwyer, L., \& Bernauer, J. (2016). Quantitative research for the qualitative researcher. In Quantitative Research for the Qualitative Researcher. https://doi.org/10.4135/9781506335674

Peterson, M., \& Webb, D. (2006). Religion and Spirituality in Quality of Life Studies. Applied Research in Quality of Life, 1(1), 107-116. https://doi.org/10.1007/s11482-006-9006$\mathrm{y}$

Purdy, M., \& Dupey, P. (2005). Holistic flow model of spiritual wellness. Counseling and Values, 49(2), 95-106. https://doi.org/10.1002/j.2161-007X.2005.tb00256.x

Religious Practices and Experiences | Pew Research Center. (2015). Retrieved from https://www.pewforum.org/2015/11/03/chapter-2-religious-practices-and-experiences/

Seeman, T. E., Dubin, L. F., \& Seeman, M. (2003). Religiosity/spirituality and health: A critical review of the evidence for biological pathways. American Psychologist, 58(1), 53-63. https://doi.org/10.1037/0003-066X.58.1.53

Skevington, S. M., Lotfy, M., \& O'Connell, K. A. (2004). The World Health Organization's WHOQOL-BREF quality of life assessment: Psychometric properties and results of the international field trial. A Report from the WHOQOL Group. Quality of Life Research, 13(2), 299-310. https://doi.org/10.1023/B:QURE.0000018486.91360.00

Vader, J.-P. (2006). Spiritual health: the next frontier. European Journal of Public Health, 16(5), 457-457. https://doi.org/10.1093/eurpub/ck1234

Vecchione, M., Alessandri, G., \& Marsicano, G. (2014). Academic motivation predicts educational attainment: Does gender make a difference? Learning and Individual Differences, 32, 124-131. https://doi.org/10.1016/j.lindif.2014.01.003

Wang, J. (2013). Pearson correlation coefficient. In Encyclopedia of Systems Biology (pp. 1671-1671). https://doi.org/10.1007/978-1-4419-9863-7_372

White, M. (2016). Spirituality self-care practices as a mediator between quality of life and depression. Religions, 7(5), 54. https://doi.org/10.3390/rel7050054

WHO | The World Health Organization Quality of Life (WHOQOL). (2019). WHO. Retrieved from https://www.who.int/mental_health/publications/whoqol/en/

WHO | WHOQOL: Measuring quality of life. (2014). WHO. Retrieved from https://www.who.int/healthinfo/survey/whoqol-qualityoflife/en/

Williams, G., Thomas, K., Smith, A. P., Williams, G., Thomas, K., \& Smith, A. P. (2017). Stress and well-being of university staff: An investigation using the DemandsResources- Individual Effects (DRIVE) Model and Well-Being Process Questionnaire (WPQ). Psychology, 08(12), 1919-1940. https://doi.org/10.4236/psych.2017.812124 